\section{Development of an instrument to measure the quality of standardized/simulated patient verbal feedback}

\author{
Win May, Dixie Fisher, Denise Souder \\ Keck School of Medicine of the University \\ of Southern California, Los Angeles, USA
}

\section{Abstract}

Standardized/simulated patients (SPs) are being asked to provide formative verbal feedback to medical students. There is a need to objectively measure the quality of this feedback. This paper describes the theoretical and empirical development of the Quality of Standardized Patient Feedback form (QSF), an instrument designed to measure the quality of standardized/simulated patient verbal feedback. The QSF consists of 7 categories derived from existing literature on feedback. Interrater and internal consistency reliabilities of QSF scores were calculated through two pilot studies. In the first, 2 standardized patient educators (SPEs) analyzed 14 videos of SP verbal feedback (weighted kappa $=0.73$ ). In the second study, 14 SPs rated 3 videos (Intraclass correlation coefficient $=0.92$. Internal reliability was 0.79 (Cronbach's alpha). Twenty-one expert SPEs were asked to rate the QSF categories as to their importance in providing feedback to learners. SPEs agreed on the importance of five of the seven categories, but were split on the importance of two categories. We found theoretical and practical support for the QSF categories. The QSF is a useful instrument for evaluating the quality of SP verbal feedback.

\section{Introduction}

Traditionally, the role of standardized/simulated patients (SPs) has been to portray patients during student teaching and testing. SPs are usually skilled and consistent at simulating real patients in terms of providing patient history and physical findings,${ }^{1-3}$ but we found they are less skilled in providing feedback. More often now, SPs are being asked to provide formative feedback to learners from the perspective of the patient. ${ }^{1,4,5}$ Receiving direct and candid feedback from a patient's viewpoint provides a rare opportunity for medical students and physicians to hear how their communication is perceived, ${ }^{6}$ and this feedback can be a powerful influence on learning, achievement $^{7,8}$ and motivational levels. ${ }^{9}$ Although efficacy of SP feedback has been measured from the students' viewpoint, ${ }^{10}$ a search of the literature revealed only one instrument, Maastricht Assessment of Simulated Patients (MaSP), that contained a verbal feedback assessment scale for SPs. ${ }^{11}$ The feedback scale of the MaSP lacked some items relevant for SP verbal feedback, and contained items considered irrelevant in our program. We found no instruments that quantified the quality of SP verbal feedback.

To meet the above need, the QSF was developed and published as part of a SP training package. ${ }^{12,13}$ However, the theoretical development and reliability of the instrument has never been reported. This paper describes the QSF's theoretical rationale and reliability data.

\section{Innovation}

The setting for developing the QSF was a U.S. medical school SP training program. The development involved twenty-eight SPs.

We selected the principles, characteristics, and models of providing feedback most relevant for SP verbal feedback, and condensed them into seven categories divided into 19 items (Figure 1). Theories on effective feedback predominantly involved feedback to learners by faculty. ${ }^{14-20} \mathrm{SPs}$ in our institution are specifically instructed by SPEs not to provide feedback on medical content of cases they portray. The areas of an encounter that SPs best provide feedback relate to the patient/physician interaction (interpersonal and communication skills) from the patient's point of view. The following were the theoretical rationale for inclusion of each category.

\section{Standardized/simulated patients asked student to reflect.}

Reflection is essential for a practitioner to identify gaps in performance, and numerous organizations have called for the incorporation of reflection at all three levels of medical education. $^{21-23}$ The effectiveness of feedback is enhanced if learners are trained to reflect and self-assess. ${ }^{24}$

\section{Standardized/simulated patients gave specific positive feedback}

After receiving positive feedback, students were more likely to be interested in and persist in the activity, ${ }^{25}$ but feedback needed to be specific to what was observed. ${ }^{26}$ Providing positive feedback prior to negative (constructive) feedback made negative feedback much more acceptable. $^{27}$
Correspondence: Win May, Keck School of Medicine of the University of Southern California, 1975 Zonal Avenue, KAM 100C, Los Angeles, 90089, USA.

Tel. +1.323.442.2830 - Fax: +1.323.442-2832.

E-mail: winmay@usc.edu

Key words: standardized/simulated patients, quality of standardized patient feedback form.

Conflict of interest: the authors report no conflicts of interest.

Received for publication: 3 August 2011.

Revision received: 10 February 2012.

Accepted for publication: 22 February 2012.

This work is licensed under a Creative Commons Attribution NonCommercial 3.0 License (CC BYNC 3.0).

(C) Copyright W. May et al., 2012

Licensee PAGEPress srl, Italy

Medical Education Development 2012; 2:e3

doi:10.4081/med.2012.e3

\section{Standardized/simulated patients gave constructive feedback}

Constructive/corrective feedback was considered essential for motivating and unfreezing recipients from their typical patterns of thought and behavior. ${ }^{28}$ Specific and behavioral feedback is generally more powerful and effective than general and emotional feedback, ${ }^{20}$ and corrective feedback was regarded as helpful by the recipient when delivered appropriately. ${ }^{29}$

\section{Standardized/simulated patients showed empathy for distressed student}

Emotions can take up space in working memory and can interfere with cognitive processing and motivation. ${ }^{30}$ The QSF requires SPs to be aware of the emotional environment, and act in an empathic manner when necessary. Inclusion of this category was supported by the PEARLS approach to feedback with the E standing for empathic understanding. ${ }^{31}$

\section{Standardized/simulated patients finished with positive feedback (sandwich)}

Research has consistently identified the sequence of constructive/corrective feedback delivery to be an important factor in acceptance..$^{32}$ Corrective feedback was found to be more acceptable when it either followed or was sandwiched between positive feedback messages. ${ }^{33}$ 


\section{Standardized/simulated patients verified student's learning}

Hearing a student summarize feedback may reveal any misunderstandings, which the SP can immediately correct. ${ }^{34}$

\section{At end of session, standardized/ simulated patients asked student if $s$ /he had other questions}

Asking the student whether he or she had any questions about the encounter allowed students to further reflect upon the encounter and to clarify fuzzy feedback. ${ }^{26}$ Thanking the student models social courtesy and ends the encounter on a positive note, increasing the likelihood that the student will remember and apply what was heard. ${ }^{27}$

The greatest challenges in developing the QSF were i) determining the most relevent factors that contribute to the concept of quality of verbal feedback, ii) choosing the optimum number of items for both reliability and ease of evaluation, and iii) wording the items so they were free of ambiguity to raters.

\section{Evaluation}

\section{Reliability}

We evaluated the inter-rater reliability and the internal reliability of the QSF using kappa, ICC and Cronbach's alpha. In study one, two experienced SPEs used the QSF to independently rate 14 randomly selected videos in which SPs gave verbal feedback to students.

In study two, we asked 14 SPs to use the QSF to independently rate three recorded video encounters of other SPs giving feedback to students.

Rater agreement between two SPEs rating the same videos was 0.73 (weighted kappa), indicating acceptable inter-rater agreement. When 14 SPs rated three videos, the intraclass correlation coefficient (ICC 2,1$)$ was 0.92 , suggesting a high level of rater agreement among these SPs. This model of ICC was chosen because all 14 SPs rated the three videos and they were considered a subset of all SPs. Internal reliability for six categories was 0.79 (Cronbach's alpha). Category IV (empathy) was dropped from the analysis because no students exhibited distress in the videos viewed. Item-test correlation of the category scores showed that each score correlated favorably with the overall scale (Table 1). Schlegel et al. (2012) reported on a modified version of the QSF (mQSF) used in Switzerland, and found acceptable validity evidence. Reliabilities ranged from 0.63 with one judge on one occasion to 0.88 using three judges and three occasions. Internal reliability (Cronbach's alpha) with 17 items was 0.80 .35

\section{Content validity}

In 2010, we surveyed 21 SPEs listed in the Association of Standardized Patient Educators registry to ascertain how essential they thought each category on the QSF was for effective feedback. The survey listed the category followed by four choices: essential, preferable, optional, not needed. The SPEs rated most of the categories on the QSF as being essential or preferable, but were nearly equally split on whether addressing student distress and providing additional positive feedback were needed for effective feedback (Table 2). Similarly, Schlegel found that one of the lowest rated items was item 12 : SP confirmed the feelings with student - an item under Category 4 SP showed empathy for distressed student.

\section{Conclusions}

We found theoretical and practical support for all of the QSF categories. QSF scores showed favorable internal and inter-rater reliabilities. We therefore conclude that the QSF is a useful instrument for evaluating the quality of SP verbal feedback.

Future studies will explore the effectiveness of the QSF to standardize and improve quality of verbal feedback by SPs.

Table 1. Item-test correlations by categories.

\begin{tabular}{lccc}
\hline Category & Item-test correlation & Item-rest correlation & $\alpha^{*}$ \\
I. SP asked student to reflect (4 items) & 0.4396 & 0.2277 & 0.8299 \\
II. SP gave positive feedback (3 items) & 0.7895 & 0.7041 & 0.7380 \\
\hline III. SP gave constructive feedback (3 items) & 0.6829 & 0.4803 & 0.7839 \\
V. SPs finished with positive feedback ( 1 item) & 0.8802 & 0.8139 & 0.7024 \\
\hline VI. SP verified student's learning (2 items) & 0.8818 & 0.7663 & 0.7008 \\
VII. SP asked if student had other questions (2 items) & 0.5825 & 0.4629 & 0.7836 \\
\hline Total scale & 0.7936 & & \\
\hline
\end{tabular}

*Internal reliability coefficient of the test if item is removed. Note: Category IV (Empathy) omitted because constant in the sample; SP, standardized/simulated patient.

Table 2. Standardized patient educators' ratings of quality of standardized patient feedback form categories (cells indicate n. selecting each category).

\begin{tabular}{|c|c|c|c|c|c|}
\hline \multicolumn{2}{|c|}{ Category } & \multirow{2}{*}{$\begin{array}{c}\text { Essential } \\
17\end{array}$} & \multirow{2}{*}{$\begin{array}{c}\text { Preferable } \\
\qquad 4\end{array}$} & \multirow{2}{*}{$\begin{array}{c}\text { Optional } \\
0\end{array}$} & \multirow{2}{*}{$\begin{array}{c}\text { Not needed } \\
0\end{array}$} \\
\hline I. & Ask student to reflect & & & & \\
\hline II. & Give specific positive feedback & 16 & 4 & 0 & 1 \\
\hline III. & Give specific constructive feedback & 19 & 1 & 0 & 1 \\
\hline IV. & Address student distress/defensiveness & 5 & 6 & 8 & 1 \\
\hline V. & Add additional positive feedback & 4 & 7 & 7 & 2 \\
\hline VI & Verify student can recall feedback & 5 & 10 & 3 & 2 \\
\hline VII & Ask whether student has questions & 13 & 4 & 4 & 0 \\
\hline VII & Thank the student & 12 & 3 & 5 & 1 \\
\hline
\end{tabular}


Date_

Case ID

Rater ID

1. SP asked student to reflect

1. SP: So, how do you think it went?

2. SP: So, what are some things you think you did well?

3. SP: Is there anything you would do or say differently if you could do this over again?

4. Gave student adequate time to answer questions before continuing

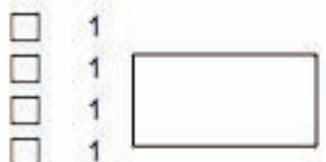

II. SP gave positive feedback

5. SP first gave positive feedback

6. SP's positive feedback referred to specific changeable behaviors

(Check if positive feedback MOSTLY specific - some generalization okay)

7. SP gave feedback from patient's perspective

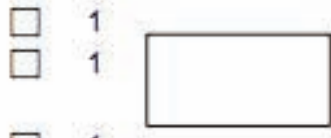

1

III. SP gave constructive feed back

8. SP's negative feedback referred to specific changeable behaviors (feedback not destructive)

9. SP limited the constructive feedback to 2 or fewer points.

10. SP gave constructive feedback from patient's perspective.

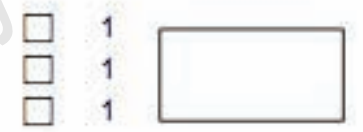

IV. SP showed empathy for distressed student (if student not distressed go to question \#14)

11. SP stopped feedback and acknowledged students' feelings 1

SP: I'm feeling that you might be upset by this feedback.

12. SP confirmed the feelings with student.

SP: Are you feeling [sad, angry, upset], or, ls this true?

13. SP reassured student about purpose of feedback

SP: Giving you feedback is our way to help you...

14. If student didn't appear distressed by feedback, check box at right and go to question \#15.

V. SP finished with positive feedback (sandwich)

15. SP finished feedback on a positive note.

VI. SP verified student's learning

16. SP asked student to summarize feedback given.

SP: What have you learned from this feedback session?

17. The SP ensured that the student understood what $\mathrm{s} / \mathrm{he}$ (the student) needed to work on

VII. At end of session, SP asked student if $s /$ he had other questions

18. SP continued to ask student if he/she had questions until student said "no."

SP: Do you have any other questions or comments? Anything else you would like to ask?

19. SP thanked the student.

SP: Thank you for your effort here today. I feel privileged to be part of your education.

1

1

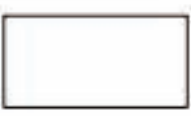

D 2006 Win May, Dixie Fisher

TOTAL SCORE

Figure 1. Quality of standardized patient Feedback Form. 


\section{References}

1. McGraw RC, O'Connor HM. Standardized patients in the early acquisition of clinical skills. Med Educ 1999;33:572-8.

2. Nagoshi MH. Role of standardized patients in medical education. Hawaii Med $\mathrm{J}$ 2001;60:323-4.

3. Peitzman SJ. Clinical skills assessment using standardized patients: perspectives from the Educational Commission for Foreign Medical Graduates. Am J Phys Med Rehabil 2000;79:490-3.

4. Eyler AE, Dicken LL, Fitzgerald JT, et al. Teaching smoking-cessation counseling to medical students using simulated patients. Am J Prev Med 1997;13:153-8.

5. Kneebone R, Kidd J, Nestel D, et al. An innovative model for teaching and learning clinical procedures. Med Educ 2002;36:628-34.

6. Bokken L, Linssen T, Scherpbier A, et al. Feedback by simulated patients in undergraduate medical education: a systematic review of the literature. Med Educ 2009;43:202-10.

7. Archer JC. State of the science in health professional education: effective feedback. Med Educ 2010;44:101-8.

8. Hattie J, Timperley H. The power of feedback. Rev Educ Res 2007;77:81-112.

9. Turan S, Ülner S, Elçin M. The impact of standardized patient's feedback on the students' motivational levels. Procedia Soc Behav Sci 2009;1:9-11.

10. Howley LD, Martindale J. The efficacy of standardized patient feedback in clinical teaching: A mixed method analysis. Med Educ Online. 2004;9:18. Available from http://www.med-ed-online.org

11. Wind LA, Van Dalen J, Muijtjens AM, Rethans JJ. Assessing simulated patients in an educational setting: the MaSP (Maastricht Assessment of Simulated Patients). Med Educ 2004;38:39-44.

12. May W, Fisher D. (2006). WinDix Training Manual for Standardized Patient Trainers:
How to Give Effective Feedback. MedEdPORTAL, 2006: (ID=171). Available from: http://services.aamc.org/jsp/mededportal/retrieveSubmissionDetailById.do?s ubId $=171$

13. Fisher D, May W. WinDix Training Manual for Standardized Patients: How to Give Effective Feedback. MedEdPORTAL:2006 : (ID=172). Available from: http://services. aamc.org/30/mededportal/servlet/s/segment/mededportal/find_resources/browse/ ?subid $=172$

14. Chowdhury RR, Kalu G. Learning to give feedback in medical education. Obstet Gynaecol 2004;6:243-7.

15. Ende J. Feedback in clinical medical education. JAMA. 1983;250:777-81.

16. Gordon J. ABC of learning and teaching in medicine: one to one teaching and feedback. BMJ. 2003;326:543-5.

17. Ovando MN. Constructive feedback: A key to successful teaching and learning. Int $\mathrm{J}$ Educ Manage 1994;8:19-22.

18. Pendleton D, Schofield T, Tate P, Havelock P. The New Consultation: Developing Doctor Patient Communication. Oxford: Oxford University Press; 2003.

19. Schum TR, Krippendorf RL. Feedback notes: a system for feedback to students and residents. Advanced Education Faculty Development Group. Acad Med 2000;75: 556-7.

20. van de Ridder JM, Stokking KM, McGaghie WC, ten Cate 0T. What is feedback in clinical education? Med Educ 2008;42:189-97.

21. ACGME Core Competencies 1999. Available from: www.mcw.edu/Medical School/EducationalServices/GraduateMedi calEducation/ACGMECoreCompetencies.h tm

22. The CanMeds 2005 Physician Competency Framework: CanMeds 2005 booklet. Ottawa: Royal College of Physicians and Surgeons of Canada 2005; 2005.

23. General Medical Council. Tomorrow's Doctors 2003. Available from: http://www.gmc-uk.org/education/undergraduate/tomorrows_doctors_2003.asp
24. Ewell PT. Organizing for learning: A point of entry. 1997. Available from: http://www. intime.uni.edu/model/learning/learn_sum mary.html

25. Deci EL, Koestner R, Ryan RM. A metaanalytic review of experiments examining the effects of extrinsic rewards on intrinsic motivation. Psychol Bull 1999;125:62768.

26. Ovando MN. Building instructional leaders' capacity to deliver constructive feedback to teachers. J Pers Eval Educ 2005;18:171-83.

27. Kivlinghan D. Feedback in group psychotherapy: review and implications. Small Gr Behav 1985;16:387-96.

28. Stoller F. Focused feedback with videotape: Extending the group's functions. Springfield: Charles C. Thomas; 1968.

29. Hewson MG, Little ML. Giving feedback in medical education: verification of recommended techniques. J Gen Intern Med 1998;13:111-6.

30. Pekrun R. The impact of emotions on learning and achievement: towards a theory of cognitive/motivational mediators. Appl Psychol 1992;41:359-76.

31. Milan FB, Parish SJ, Reichgott MJ. A model for educational feedback based on clinical communication skills strategies: beyond the feedback sandwich. Teach Learn Med 2006;18:42-7.

32. Morran DK, Stockton K, Cline R, et al. Facilitating feedback exchange in groups: Leader interventions. J Specialists Gr Work 1998;23:257-68.

33. Davies D, Jacobs A. Sandwiching complex interpersonal feedback. Small Gr Behav 1985;16:387-96.

34. Morran DK, Stockton R, Hams M. Analysis of group leader and member feedback messages. J Gr Psychother, Psychodrama, Sociometry 1991;44:126-35.

35. Schlegel C, Woermann U, Rethans JJ, et al. Validity evidence and reliability of a Simulated Patient Feedback Instrument. BMC Med Edu 2012; 12:6. 